\title{
Parallel Exploratory And Confirmatory Factor Analysis Of The Hungarian Fear Of Covid-19 Scale In A Large General Population Sample: A Psychometric And Dimensionality Evaluation
}

\section{Péter György Balázs}

Corvinus University of Budapest

\section{Mitev Ariel}

Corvinus University of Budapest

Valentin Brodszky ( $\square$ valentin.brodszky@uni-corvinus.hu )

Corvinus University of Budapest

\section{Research Article}

Keywords: COVID-19, fear, confirmatory factor analysis, Hungarian FCV-19S, psychometrics

Posted Date: March 7th, 2022

DOI: https://doi.org/10.21203/rs.3.rs-1393510/v1

License: (c) (1) This work is licensed under a Creative Commons Attribution 4.0 International License.

Read Full License 


\section{Abstract}

Background: The seven-item Fear of Covid-19 Scale (FCV-19S) is the most frequently applied instruments for assessing fear of COVID-19 infection. Our objectives were to develop a Hungarian version of FCV-19S, to evaluate its psychometric properties and dimensionality.

Methods: In May 2021, a sample of adults representative of the Hungarian general population completed an online questionnaire survey with respect of the COVID-19 pandemic. Outcome measures included FCV-19S, General Anxiety Disorder (GAD-7) questionnaire and Patient Health Questionnaire (PHQ-9) depressive severity score. Item characteristics, validity and internal consistency reliability of FCV-19S were determined. Maximum likelihood method EFA was used to measure item-factor relationships ( $\mathrm{h}^{2}$; factor loading; eigenvalues), while goodness-of-fit of the FCV-19 was evaluated by comparison of one and two-factor CFA model fits (RMSEA, SRMR, $\left.\chi^{2} / \mathrm{df}, \mathrm{CFI}, \mathrm{NFI}, \mathrm{RFI}, \mathrm{IFI}, \mathrm{TLI}\right)$. Correlations explored the relationships between fear, anxiety and depression and FCV-19 scores were compared in vaccinated and non-vaccinated subgroups.

Results: Overall, $n=2000$ responded the online questionnaire. The mean age was 49.1 , majority being females (62.2\%). EFA identified a maximum of two factors (eig=4.2 and 1.01). Items 3,4,6,7 strongly correlated with Factor 1 (physiological fear) and items 1,2,5 linked to Factor 2 (emotional fear). FCV-19 items showed good internal consistency (Cronbach $a=0.88$ ) and correlated moderately or highly, while showing weak to moderate correlation with PHQ-9 $(r=0.364)$ and GAD-7 $(r=0.424)$. Significant differences were observed between vaccinated (14.2) and non-vaccinated (13.1) FCV-19 mean scores.

Conclusions: The Hungarian version of the FCV-19 Scale seems valid and reliable construct to measure fear associated with COVID-19. Both uni- and bi-dimensional CFA is feasible, though the two-factor structure faces some limitations.

\section{Introduction}

The COVID-19 pandemic raised rapid public health emergency globally from its appearance in December 2019. Hungary imposed containment phase in $2020 \mathrm{March}$, to prevent steep shift in epidemiological curve. The government implemented several pre-emptive policies such as domestic \& international travel restrictions, shuttering business activity, distance learning in public \& university education. Besides the economic backlash, sudden lockdown multiplied with the risks posed by an unknown infectious disease resulted in wide-range of impacts on health (HrQoL) of the population. Mass vaccination started in 2021 mid-January, shortly followed by the third wave of the pandemic (March-June 2021), bringing sanctuary regulations back (distance learning in public education, austere lockdown, mandatory mask-wearing in/outside) (1).

Similarly, to other countries, Hungary started to investigate several related aspects of the pandemic, including fear, anxiety, stigmatization and worries. Several studies address fear as the most contagious factor of epidemics. The uniqueness of the COVID-19 stressed that instead of utilizing generic 
psychological scales, developing a new disease-specific Fear of COVID-19 Scale (FCV-19) would be adequate.

The first survey introducing the Fear of Covid-19 Scale that has been used to measure fear associated with COVID-19 pandemic was published in March 2020 (2). Currently it has been validated in at least 40 countries and translated to more than 20 languages (see supplementary material). Also, the Hungarian version of FCV-19 has been validated in a convenient sample of university students and lecturers in 2021 (3). Despite of many existing scales measuring fear and anxiety of individuals, the crucial role of fear in response to global pandemic outbreak generated demand in research of psychology and related disciplines towards the FCV-19 scale. It is directly designed to measure fear of Covid-19 and able to identify vulnerable population groups. The rapid spread of FCV-19 implementation aggregated information in conclusions of good internal consistency, acceptable construct, convergent \& concurrent validity, with satisfactory psychometric properties of the scale. The psychometric tests of the questionnaire suggest that it is applicable in all genders and age-groups (4). However, there is a debate in the number of underlying latent factors.(5-9).

Methods of classical test theory (CTT) (e.g. item-correlations, Cronbach's a) and item response theory (IRT, also referred as modern test theory) (e.g. parameter logistic modelling, Rasch analysis) may all be used to assess the validity, reliability of a new measurement tool. Dimensionality on constructs is often explored by exploratory/confirmatory factor analysis (EFA and CFA). Several studies approved the certitude of the unidimensional structure of the FCV-19 questionnaire using either modified (10-14) or the initial model (15) one-factor confirmatory factor analysis. Besides CTT and CFA elements, more researchers expanded the evaluation with structural equation modelling $(\operatorname{SEM})(16,17)$ or Rasch analysis $(2,18)$. When designing a new construct to measure a latent factor (e.g. fear), preferably the item numbers should be balanced related to each dimension, particularly when more than one latent factor may be present. Compared to the huge number of construct dimensionality evaluation by one-factor CFA, only few completed two-factor CFA, even fewer reported the results of EFA $(5,6,8,19)$.

\section{Methods}

\section{Participants and procedure}

A large-scale cross-sectional survey was carried out between May 25th - June 08th 2021. Panel data of a professional survey company was used for online self-completed data collection, until the broad representativeness regarding age, gender, educational level, geographical region and place of living of the Hungarian general population was reached $(N=2000)$. Inclusion criteria for the study were being aged $\geq$ 18 years and providing informed consent. Permission for conducting the study was granted by the Research Ethics Committee of Corvinus University Budapest (reference No. KRH/109/2021).

\section{Fear of Covid-19 questionnaire}


The FCV-19 questionnaire consists of seven-items scored on a five-point likert scale, with maximum overall score of 35 (indicating the highest level of fear) (2). Respondents are questioned about the extent of being afraid of coronavirus (anxiousness, losing life, uncomfortable thoughts) and the related physiological manifestations of fear (palpitating heart, clammy hands, losing sleep). Seven closed questions, each represented by one statement, rated on a 1-5 point balanced scale (' 1 ' indicating strong disagreement) measured respondents fear related to coronavirus.

\section{Translation}

The permission to translate and utilize FCV-19 scale was obtained from the developer team of the questionnaire. To adapt the FCV-19 forward-backward translation was applied supervised by two health professionals and harmonized by group discussion of more researchers. The original translation was altered in item 1 (most afraid of Covid-19) and item 5 (nervous and anxious when watching news and stories about coronavirus): to (1) being very afraid and (5) see news in social media, in order to comply cultural and semantical embedding. "Coronavirus" appellation was changed to Covid-19. The final version has been back-translated to English by a third independent native speaker, the consensus version needed no changes. (See the Hungarian version in Supplementary material).

\section{Other measurement tools}

The General Anxiety Disorder-7 (GAD-7) is a self-reported 7-item scale that measures the severity of the patient's anxiety over the past 2 weeks. Each item is rated on a 0-3 point scale, described by the frequency of anxious occasions: "not at all”, „several days”, "more than half the days”, and "nearly every day". GAD-7 total score ranges from 0 to 21 , covering four severity categories: no, mild, moderate and severe anxiety (20).

The nine item Patient Health Questionnaire (PHQ-9) rates respondents depression. The items are based on the diagnostic criteria of Diagnostic and Statistical Manual of Mental Disorders (DSM-IV). PHQ-9 is rated on a 0-3 point scale, that express frequencies of depressive states over the past two weeks (not at all - nearly every day). PHQ-9 total score for the nine items ranges from 0 to 27 , differentiating five severity categories (no problem, mild, moderate, moderately severe and severe depression) (21).

\section{Statistical analysis}

Descriptive statistics including means and central tendency measures were used to explore sample population and item characteristics (standard deviation, variance, skewness, kurtosis, floor effect, ceiling effect). Nonparametric tests (Kruskal-Wallis and Mann-Whitney) were used to compare FCV-19 overall mean scores of subgroups. Reliability of the FCV-19 questionnaire was examined by CTT, measuring items correlation (Pearson's $r$ and corrected item-total correlation) and internal consistency (Cronbach alfa). Inflation in mean estimates was assessed through ceiling and floor effect with $95 \%$ confidence interval consideration. Interpretation values for FCV-19 construct properties were set as Pearson correlation coefficient for inter item consistency $>0.3$; Cronbach alfa for internal consistency $>0.7$ and corrected item-total correlation coefficient with a value of no less than $0.5(22,23)$. Validity information 
of the 7-item construct was revealed by conducting a separate one- and two-factor model exploratory factor analysis and confirmatory factor analysis, using maximum likelihood method (24). Communalities, factor loadings, standardized estimates and regression weights were reported. Factor loadings were interpreted as acceptable if $\geq 0.3$, practically significant if $\geq 0.5$ and indicative of a well-defined structure if $\geq 0.7$ (25). Rotation method is decided based on factors correlation, distribution is considered oblige in component correlation is above 0.4 ). Modification indices above covariance discrepancy threshold of 40 (to minimize the number of the covariances drawn) were done, step by step, for both confirmatory factor analysis (CFA) models in order to improve the fit. Absolute model fit measures in terms of root mean square error of approximation (RMSEA), standardized mean root square residual (SRMR), chi square and degree of freedom, comparative fit index (CFI) were compared, such as incremental model fit indices of Tucker-Lewis index (TLI), normed fit index (NFI), relative fit index (RFI), incremental fit index (IFI). Common threshold values were used both for RMSEA and SRMR $\leq 0.06$ (26) and for CFI > 0.90 (27). Convergent validity between FCV-19 Scale and two health measurement tools GAD-7 and PHQ-9 was noted. Statistical analysis was carried out using IBM SPSS and AMOS (Version 25.0. Armonk, NY: IBM Corp).

\section{Results}

\section{Population characteristics}

Overall, 2421 started the questionnaire, the final representative sample consists of 2000 complete responses (response rate: $82.6 \%$ ) The mean age was $49.1(\mathrm{SD}=15.3)$, majority of the population was female $(n=1244 ; 62.2 \%)$. Education level of respondents in primary, secondary and tertiary school distributed as follows: $21.8 \%, 45.0 \%, 33.2 \%$. Majority of the sample population has been vaccinated $(n=67.3 \%)$, and $18.5 \%(n=370)$ already encountered the infection. At the time of data collection altogether 5.1 million people (53\%) in Hungary were vaccinated at least once (28). (Table 1)

Table 1 - Population characteristics and means 


\begin{tabular}{|c|c|c|c|c|c|}
\hline \multicolumn{2}{|l|}{ Variable } & \multirow{2}{*}{$\begin{array}{l}n \\
2000\end{array}$} & \multirow{2}{*}{$\begin{array}{l}\% \\
100\end{array}$} & \multirow{2}{*}{$\begin{array}{l}\text { FCV-19 score (SD) } \\
13.9(5.5)\end{array}$} & \multirow[t]{2}{*}{$p$ value* } \\
\hline Total & & & & & \\
\hline \multirow[t]{3}{*}{ Age group } & $18-34$ & 437 & 21.9 & $13.5(5.8)$ & \multirow[t]{3}{*}{0.001} \\
\hline & $35-54$ & 763 & 38.1 & $13.7(5.7)$ & \\
\hline & $55<$ & 800 & 40.0 & $14.3(5.2)$ & \\
\hline \multirow[t]{2}{*}{ Gender } & male & 756 & 37.8 & $13.1(5.3)$ & \multirow[t]{2}{*}{0.000} \\
\hline & female & 1244 & 62.2 & $14.4(5.7)$ & \\
\hline \multirow[t]{3}{*}{ Educational level } & primary & 435 & 21.8 & $14.7(6.6)$ & \multirow[t]{3}{*}{0.166} \\
\hline & secondary & 900 & 45.0 & $13.8(5.4)$ & \\
\hline & tertiary & 665 & 33.2 & $13.5(4.9)$ & \\
\hline \multirow[t]{2}{*}{ Vaccinated } & yes & 1347 & 67.3 & $14.2(5.3)$ & \multirow[t]{2}{*}{0.000} \\
\hline & no & 653 & 32.7 & $13.1(6.0)$ & \\
\hline \multirow[t]{2}{*}{ Infected } & yes & 370 & 18.5 & $13.8(5.7)$ & \multirow[t]{2}{*}{0.551} \\
\hline & no & 1630 & 81.5 & $13.9(5.5)$ & \\
\hline
\end{tabular}

* Known-group validity was assessed by the appropriate Kruskal-Wallis $\mathrm{H}$ or Mann-Whitney $\mathrm{U}$ nonparametric test (significant if $p<0.05$ )

Total fear average score out of the possible maximum of 35 on FCV-19 scale was $13.9(S D=5.5)$. Central tendency measures suggest that all people agreed the most with the statements 1,2 and 5 indicating the highest impact of unpleasant thinking, being afraid, and seeing news of COVID-19 on fear level and statement $1(n=26 \%), 2$ ( $n=32 \%), 5(n=16 \%)$ had the highest number of agreements. While the same items $(1,2$ and 5$)$ indicated the greatest uncertainty $(n=32 \%, 25 \%, 25 \%)$. Response distribution among items, showed gravitation towards high disagreement in questions $3(n=83 \%), 4(n=79 \%), 6(n=91 \%)$ and 7 $(n=88 \%)$ (Figure 1). Nonparametric t-tests revealed significant differences in FCV-19 scores among separate age $(p<0.01)$, gender $(p<0.001)$ and vaccination groups $(p<0.001)$. Older individuals $($ aged $>55+)$, women and vaccinated had higher mean scores, demonstrating elevated fear from COVID-19.

Health status measures all correlated significantly $(p<0.01)$ on slight to moderate level with the FCV-19 scale: GAD-7 ( $r=0.424)$; PHQ-9 ( $r=0.364)$; EQ-anxiety/depression dimension-5L (rho=0.272), EQ-5D-5L index $(r=-0.207)$.

Figure 1 - Distribution of responses among FCV-19 items

Table 2 - Descriptive statistics of item responses 
Descriptive statistics of items in total sample

\begin{tabular}{lcccccccc}
\hline Item & $\mathrm{n}$ & mean & $\mathrm{SD}$ & skewness & kurtosis & floor \% & ceiling \% & Item variance \\
\hline Item \#1 & 2000 & 2.68 & 1.23 & 0.13 & -0.93 & 23.4 & 7.8 & 1.51 \\
\hline Item \#2 & 2000 & 2.76 & 1.29 & 0.05 & -1.15 & 23.7 & 9.0 & 1.67 \\
\hline Item \#3 & 2000 & 1.52 & 0.86 & 1.92 & 3.74 & 65.2 & 1.7 & 0.74 \\
\hline Item \#4 & 2000 & 1.76 & 0.99 & 1.27 & 1.05 & 53.5 & 2.1 & 0.98 \\
\hline Item \#5 & 2000 & 2.25 & 1.22 & 0.59 & -0.7 & 38.2 & 5.3 & 1.48 \\
\hline Item \#6 & 2000 & 1.43 & 0.77 & 2.11 & 4.89 & 69.7 & 1.0 & 0.59 \\
\hline Item \#7 & 2000 & 1.49 & 0.84 & 1.89 & 3.5 & 67.7 & 1.2 & 0.7 \\
\hline Descriptive statistics of items in vaccinated group & & & & \\
\hline Item \#1 & 1347 & 2.85 & 1.19 & -0.04 & -0.87 & 17.4 & 8.4 & 1.43 \\
\hline Item \#2 & 1347 & 2.84 & 1.25 & -0.04 & -1.07 & 19.5 & 8.3 & 1.55 \\
\hline Item \#3 & 1347 & 1.54 & 0.83 & 1.73 & 2.95 & 62.8 & 1.0 & 0.7 \\
\hline Item \#4 & 1347 & 1.8 & 0.98 & 1.15 & 0.76 & 50.3 & 1.8 & 0.96 \\
\hline Item \#5 & 1347 & 2.29 & 1.19 & 0.47 & -0.8 & 35.3 & 4.3 & 1.42 \\
\hline Item \#6 & 1347 & 1.43 & 0.73 & 1.89 & 3.71 & 68.7 & 0.4 & 0.54 \\
\hline Item \#7 & 1347 & 1.49 & 0.82 & 1.77 & 2.85 & 67.1 & 0.7 & 0.67 \\
\hline Descriptive statistics of items in non-vaccinated group & & & \\
\hline Item \#1 & 653 & 2.31 & 1.22 & 0.53 & -0.63 & 35.5 & 6.6 & 1.49 \\
\hline Item \#2 & 653 & 2.59 & 1.37 & 0.26 & -1.2 & 32.2 & 10.6 & 1.88 \\
\hline Item \#3 & 653 & 1.49 & 0.92 & 2.24 & 4.9 & 70.1 & 2.9 & 0.85 \\
\hline Item \#4 & 653 & 1.68 & 1 & 1.52 & 1.76 & 60.2 & 2.8 & 1.01 \\
\hline Item \#5 & 653 & 2.15 & 1.27 & 0.81 & -0.45 & 44.0 & 7.2 & 1.62 \\
\hline Item \#6 & 653 & 1.43 & 0.84 & 2.38 & 6.03 & 71.7 & 2.1 & 0.71 \\
\hline Item \#7 & 653 & 1.49 & 0.87 & 2.11 & 4.58 & 68.9 & 2.1 & 0.75 \\
\hline
\end{tabular}

\section{Consistency and factor analysis measures}


The total internal consistency of the COVID-19 fear questionnaire was good (Cronbach $a=0.88$ ), all items indicated proper internal consistency, corrected item-total correlations of items range between 0.62-0.75. All seven items were significantly correlating $(p<0.001)$ on a moderate to high level $(r=0.357-812)$, expressing acceptable instrument validity and enabling factor analysis (Kaiser-Meyer-Olkin measure $=$ $0.858 ; p<0.001)$. (Table 3)

Table 3 - Correlation of the seven item FCV-19

\begin{tabular}{|c|c|c|c|c|c|c|c|c|c|}
\hline \multicolumn{10}{|c|}{ Pearson's correlation of items } \\
\hline $\begin{array}{l}\text { FCV } \\
\text { items }\end{array}$ & $\begin{array}{l}\text { Item } \\
\# 1\end{array}$ & $\begin{array}{l}\text { Item } \\
\text { \#2 }\end{array}$ & $\begin{array}{l}\text { Item } \\
\# 3\end{array}$ & $\begin{array}{l}\text { Item } \\
\# 4\end{array}$ & $\begin{array}{l}\text { Item } \\
\# 5\end{array}$ & $\begin{array}{l}\text { Item } \\
\# 6\end{array}$ & $\begin{array}{l}\text { Item } \\
\# 7\end{array}$ & $\begin{array}{l}\text { Corrected } \\
\text { item-total } \\
\text { correlation }\end{array}$ & $\begin{array}{l}\text { Cronbach } \\
\text { alfa if item } \\
\text { deleted }\end{array}$ \\
\hline $\begin{array}{l}\text { Item } \\
\# 1\end{array}$ & 1 & & & & & & & 0.617 & 0.866 \\
\hline $\begin{array}{l}\text { Item } \\
\# 2\end{array}$ & 0.601 & 1 & & & & & & 0.626 & 0.866 \\
\hline $\begin{array}{l}\text { Item } \\
\# 3\end{array}$ & 0.403 & 0.402 & 1 & & & & & 0.663 & 0.859 \\
\hline $\begin{array}{l}\text { Item } \\
\# 4\end{array}$ & 0.544 & 0.471 & 0.652 & 1 & & & & 0.749 & 0.847 \\
\hline $\begin{array}{l}\text { Item } \\
\# 5\end{array}$ & 0.499 & 0.611 & 0.494 & 0.589 & 1 & & & 0.699 & 0.853 \\
\hline $\begin{array}{l}\text { Item } \\
\# 6\end{array}$ & 0.366 & 0.357 & 0.625 & 0.618 & 0.486 & 1 & & 0.666 & 0.861 \\
\hline $\begin{array}{l}\text { Item } \\
\# 7\end{array}$ & 0.418 & 0.405 & 0.634 & 0.646 & 0.537 & 0.812 & 1 & 0.711 & 0.855 \\
\hline
\end{tabular}

Results of one-factor exploratory factor analysis show that item 4, 6 and 7 have relatively high level of common variance $\left(h^{2}=0.65 ; 0.67 ; 0.72\right)$. Total variance explained by the one-factor model was $60.1 \%$, with component's eigenvalue $=4.21$. Oblimin rotation with Kaiser normalization was applied in case of the twofactor model (coefficients smaller than 0.38 were supressed). All items have moderate/high shared variance of other variables $\left(h^{2}=0.54-0.81\right)$. Factor loading shows that questions $1,2,5$ likely belong to Factor 1, named as "emotional impact of fear" based on item correlation strength. Questions 3,4,6,7 are strongly related to Factor 2, named as "physiological impact of fear". The second components eigenvalue was 1.01 , the two factors had a cumulative variance of $74.6 \%$. (Table 4 )

Table 4 - Results of exploratory factor analysis 
EFA of item properties

\begin{tabular}{|c|c|c|c|c|c|}
\hline \multirow{3}{*}{$\begin{array}{l}\text { Item } \\
\text { (question) }\end{array}$} & \multicolumn{2}{|c|}{ One-factor model } & \multicolumn{3}{|c|}{ Two-factor model } \\
\hline & \multirow{2}{*}{$\begin{array}{l}\text { Communality } \\
\left(\mathrm{h}^{2}\right)\end{array}$} & \multirow{2}{*}{$\begin{array}{l}\text { Factor matrix ( } 1 \\
\text { factor loading) }\end{array}$} & \multirow{2}{*}{$\begin{array}{l}\text { Communality } \\
\left(\mathrm{h}^{2}\right)\end{array}$} & \multicolumn{2}{|l|}{ Factor matrix } \\
\hline & & & & $\begin{array}{l}1- \\
\text { physiological } \\
\text { factor }\end{array}$ & $\begin{array}{l}\text { 2-emotional } \\
\text { factor }\end{array}$ \\
\hline Item-1 & 0.333 & 0.577 & 0.536 & \multirow[t]{3}{*}{-} & 0.722 \\
\hline Item-2 & 0.323 & 0.568 & 0.641 & & 0.846 \\
\hline Item-5 & 0.469 & 0.685 & 0.583 & & 0.613 \\
\hline Item-3 & 0.573 & 0.757 & 0.543 & 0.603 & - \\
\hline Item-4 & 0.645 & 0.803 & 0.622 & 0.502 & \\
\hline Item-6 & 0.669 & 0.818 & 0.806 & 0.960 & \\
\hline Item-7 & 0.722 & 0.850 & 0.809 & 0.903 & \\
\hline
\end{tabular}

The single-factor (unidimensional) confirmatory factor analysis estimated unit change in standard deviation of items between $0.53-0.85$, modest in case of item 6 , highest in item 4 (Table 5). Fixed regression weight was the only declining in item 6 (unstenderdized $\beta=0.88$ ). Predicted variance of items ranged between 28.1-72.4\%. Modification indices suggested to covariate error terms of Item 7-6; 2-1; 5-2 and $5-1$. All covariated pairs of residuals improved the baseline model (RMSEA $=0.22$ vs 0.16 vs 0.13 vs 0.86 vs 0.72 ). Despite the correlation of error variances in the unidimensional structure, model fit indicators of RMSEA and CMIN/df were higher in baseline and all following models compared to the twofactor model. Three covariated error term pairs (Item 7-6; 5-1; 4-1) resulted the best model fit in case of the two-factor structure, all improving the baseline model (RMSEA $=0.15$ vs 0.10 vs 0.73 vs 0.61 ). Predictors of items explained $51.8-77.4 \%$ of items variance. In comparison to the one-factor model, the error variance of items ranged on a smaller scale (22.6-42.8\% vs $27.6-71.9 \%)$. The one-unit change (in standard deviation) impact of Emotional fear factor on items $1,2,5(\beta=0.79 ; 0.72 ; 0.88)$ was similar to the impact of Physiological fear factor on items $3,4,6,7(\beta=0.79 ; 0.84 ; 0.75 ; 0.79)$. Fear declined in items $1 \& 2$ (most afraid \& uncomfortable to think on coronavirus-19) due Emotional fear factor (unstandardized $\beta=0.90$ and 0.87 ). Fear was elevating in items $3 \& 4$ (clammy hands \& losing life) because of Physiological fear factor (unstandardized $\beta=1.03$ and 1.26). Factor $1 \& 2$ showed linear covariation (0.51) and significant high level of correlation $(r=0.73)$.

5. Table - Results of one and two-factor CFA 


\section{One-factor model}

\begin{tabular}{|c|c|c|c|c|}
\hline Item & Latent factor & $\begin{array}{l}\text { estimate (stand. } \\
\text { reg. weight) }\end{array}$ & $\begin{array}{l}\text { regression weight } \\
(S E .)\end{array}$ & $\begin{array}{l}\text { squared } \\
\text { loading }(\mathrm{S} m \mathrm{C})\end{array}$ \\
\hline$\# 1$ & \multirow[t]{7}{*}{ Fear } & 0.573 & $1.08(0.04)$ & 0.328 \\
\hline \#2 & & 0.530 & $1.05(0.05)$ & 0.281 \\
\hline \#3 & & 0.777 & $1.03(0.03)$ & 0.603 \\
\hline$\# 4$ & & 0.851 & $1.29(0.03)$ & 0.724 \\
\hline$\# 5$ & & 0.673 & $1.26(0.04)$ & 0.453 \\
\hline \#6 & & 0.742 & $0.88(0.02)$ & 0.541 \\
\hline$\# 7$ & & 0.779 & $1.00(-)$ & 0.606 \\
\hline \multicolumn{5}{|c|}{ One-factor model fit } \\
\hline $\begin{array}{l}\text { Statistical } \\
\text { measure }\end{array}$ & Test indices & Test Results & $\begin{array}{l}\text { Test standard } \\
\text { (unit value) }\end{array}$ & Model fit \\
\hline \multirow{4}{*}{$\begin{array}{l}\text { Model } \\
\text { absolute fit }\end{array}$} & RMSEA & 0.075 & $<0.06$ & good \\
\hline & $\mathrm{CMIN} / \mathrm{df}$ & 11.45 & $<5.0$ & not optimal \\
\hline & chi squared $p$ & 0.001 & $>0.05$ & not optimal \\
\hline & SRMR & 0.024 & $<0.06$ & good \\
\hline \multirow{5}{*}{$\begin{array}{l}\text { Model } \\
\text { incremental fit }\end{array}$} & $\mathrm{NFI}$ & 0.986 & $>0.95$ & good \\
\hline & RFI & 0.970 & $>0.95$ & good \\
\hline & $\mathrm{IFI}$ & 0.987 & $>0.95$ & good \\
\hline & TLI & 0.972 & $>0.95$ & good \\
\hline & CFI & 0.987 & $>0.95$ & good \\
\hline
\end{tabular}

\section{Two-factor model}

\begin{tabular}{|c|c|c|c|c|}
\hline Item & Latent factor & $\begin{array}{l}\text { estimate (stand. } \\
\text { reg. weight) }\end{array}$ & regression weight & $\begin{array}{l}\text { squared } \\
\text { loading }(\mathrm{S} m c)\end{array}$ \\
\hline$\# 1$ & \multirow{3}{*}{$\begin{array}{l}\text { 1. factor: } \\
\text { emotional fear }\end{array}$} & 0.785 & $0.90(0.03)$ & 0.616 \\
\hline \#2 & & 0.720 & $0.87(0.03)$ & 0.518 \\
\hline$\# 5$ & & 0.880 & $1.00(-)$ & 0.774 \\
\hline \#3 & \multirow{3}{*}{$\begin{array}{l}\text { 2. factor: } \\
\text { physiological fear }\end{array}$} & 0.787 & $1.03(0.03)$ & 0.620 \\
\hline$\# 4$ & & 0.838 & $1.26(0.03)$ & 0.702 \\
\hline \#6 & & 0.754 & $0.88(0.02)$ & 0.568 \\
\hline
\end{tabular}




\section{Two-factor model fit}

\begin{tabular}{lllll}
\hline $\begin{array}{l}\text { Statistical } \\
\text { measure }\end{array}$ & Test indices & Test Results & $\begin{array}{l}\text { Test standard } \\
\text { (unit value) }\end{array}$ & Model fit \\
\hline $\begin{array}{l}\text { Model } \\
\text { absolute fit }\end{array}$ & RMSEA & 0.061 & $<0.08$ & very good \\
\cline { 2 - 5 } & CMIN/df & 8.53 & $<5.0$ & not optimal \\
\cline { 2 - 5 } & chi squared p & $<0.001$ & $>0.05$ & not optimal \\
\cline { 2 - 5 } & SRMR & 0.025 & $<0.06$ & good \\
\hline $\begin{array}{l}\text { Model } \\
\text { incremental fit }\end{array}$ & NFI & 0.989 & $>0.95$ & good \\
\cline { 2 - 4 } & RFI & 0.978 & $>0.95$ & good \\
\cline { 2 - 5 } & IFI & 0.991 & $>0.95$ & good \\
\cline { 2 - 4 } & TLI & 0.980 & $>0.95$ & good \\
\cline { 2 - 4 } & $\mathrm{CFI}$ & 0.991 & $>0.95$ & good
\end{tabular}

\section{Discussion}

Validation of the Hungarian version of the seven item FCV-19 questionnaire was done in 2021 May in the sample of general population $(\mathrm{N}=2000)$. Psychometric properties were analysed by descriptive statistics, methods of classical test theory were used to measure validity and reliability. Exploratory and confirmatory factor analysis were used to compare one and two-factor structure of the construct.

Differences in FCV-19 mean scores were highlighted between different age groups (18-34: 13.5; 35-54: 13.7; 55 $\leq$ : 14.3), male (13.1) and female (14.4), vaccinated (14.2) and non-vaccinated (13.1) population groups. Correlation between anxiety (GAD-7), depression (PHQ-9) and FCV-19 was moderate $(p<0.01 ; r=$ 0.424 with GAD-7 and $r=0.364$ with PHQ-9). Item descriptive measures suggest that people agreed the most with questions 1 (afraid of COVID-19), 2 (unpleasant thinking), 5 (seeing news in social media). Vaccinated group indicated higher fear in items $1-5$ and equalled in items 6-7 compared to nonvaccinated group. Items 3 (clammy hands), 4 (losing life), 6 (cannot sleep), 7 (palpitating heart) received the biggest proportion of disagreement responses.

The Hungarian version of the FCV-19 has good level of internal consistency (Cronbach's $a=0.88$ ), and high corrected item-total correlation $(r=0.666-0.749)$. Dimensionality was assessed by one and twofactor confirmatory factor analysis, suggesting that observing two latent factors is possible, also resulted a better model fit. Although parallel analysis is required, whereas the eigenvalue of the second latent factor was arguably low $(\mathrm{eig}=1.01)$. The randomly generated correlation matrices of parallel analysis 
suggest minimum mean eigenvalue of no less than 1.05 for the second factor, demanding the one-factor model approach. Moreover, cross-country invariance comparative analysis further supported the unidimensional structure of the construct (29).

All two-factor analysis studies showed excellent model fits, the item-factor structures turned out different $(5-7,30)$. Almost every two-factor structure identified item $1,2,4,5$ belonging to one component named as "emotional response" and items 3,6,7 representing the second factor called as

"physiological/psychological response" $(5,7,8,19,30,31)$. In the structure of Iversen et al. (6) items 1,2,4 represented "cognitive fear" factor and 3,5,6,7 the "somatic fear" factor. Our two-factor structure is unique with identical similarities: physiological fear factor consists of items $3,4,6,7$ and emotional fear of items $1,2,5$. The weakest element in our two-factor structure, shown by the pattern matrix was item 4 (better correlating with the physiological factor: 0.50 vs 0.37 ). Nevertheless, item 4 potentially belongs to emotional fear dimension, CFA model fit results were better, when classifying it to psychological fear dimension. The results of one-factor models likewise in other studies also echoes strong relationship in item $1-2$ and item $6-7$, simultaneously a gap between these pairs $(9,12,13)$.

Contemporary study introduced the validation of the Hungarian version of the FCV-19 questionnaire, showing congruent results to our study, though research groups worked separately. (3) Although, minor differences in translation regarding synonyms appeared, literally the sentences were corresponding. The two study samples (convenient vs general population) and data collection time (2021 January: mid of second wave vs 2021 May: ending of the third wave) remarkably differed. Conclusions of the two studies on construct validity and reliability conclusions were similar. Dimensionality assessed only by one-factor CFA, showed dissimilar, rather poor model fit, but the items relationship was kindred.

Huge number of psychometric property and factor analysis measures followed the original Ahorsu et al. FCV-19S validation study (2). Recent study provides a dimensionality, reliability and validity assessment using one \& two-model parallel exploratory and confirmatory factor analysis. Our results are consistent with the previous findings $(11,32-34)$, emphasising that FCV-19 has reliable and valid measurement properties.

This study aimed to evaluate the (1) dimensionality, (2) validity and reliability of the Fear of Covid-19 questionnaire, although a primary limitation is posed by the timing of the data collection. Salient divergences in Covid fear could have been between the contagion peaks of the pandemic and access to vaccines both within the country and between countries. Second limitation of this study is the online data collection and convenient sampling among respondent of panel database. Considering the second factors eigenvalue $(=1.01)$, EFA and parallel analysis suggests that researchers have to be thorough when concluding the results of the two-factor model. Item 4 (losing life), unlike in other structures was stronger related to physiological factor than to emotional.

\section{Conclusion}


Our study evaluates the FCV-19 questionnaire by reporting methodologically principal information such as factors eigenvalues, apart other model choice considerations (e.g. implemented modification indices). Nevertheless, the Hungarian FCV-19 proved to be valid and reliable construct to measure the impact of fear associated with the COVID-19 pandemic. We hope that our results encourage further research and may assist in the planning of COVID-19 related health policies.

\section{Declarations}

Ethics approval and consent: The study followed the Helsinki Declaration guidelines. All participants were adults (18 $\leq$ ) who provided informal consent. Ad Hoc Research Ethics Committee at the Corvinus University of Budapest granted the ethical approval (KRH/109/2021).

Consent for publication: not applicable

Availability of data: The datasets used and/or analysed during the current study are available from the corresponding author

Competing interests: Authors declare no conflict of interest.

Funding: Partial financial support was received from Corvinus University publication grant (EFOP-3.6.3VEKOP-16-2017-00007) for PhD students. Data collection was supported by the Higher Education Institutional Excellence Program 2020 of the Ministry of Innovation and Technology in Hungary in the framework of the Financial and Public Services research project (TKP2020-IKA-02) at the Corvinus University of Budapest.

Author's contribution: All authors contributed to questionnaire development. PB and VB designed the study concept. Statistical analysis were performed by PB and AM. The first draft of the manuscript was written by PB and all authors contributed to the critical revision of the paper. All authors read and accepted the final version of manuscript.

Acknowledgements: not applicable

\section{References}

1. Domestic law (no. I.), (2021).

2. Ahorsu DK, Lin CY, Imani V, Saffari M, Griffiths MD, Pakpour AH. The Fear of COVID-19 Scale: Development and Initial Validation. International journal of mental health and addiction. 2020; doi:10.1007/s11469-020-00270-8

3. Stankovic M, Papp L, Nyúl B, Ivánkovits L, Pető Z, Töreki A. Adaptation and psychometric evaluation of Hungarian version of the Fear of COVID-19 Scale. PloS one. 2021; doi:10.1371/journal.pone.0261745 
4. Sakib N, Bhuiyan AKMI, Hossain S, Al Mamun F, Hosen I, Abdullah AH, et al. Psychometric Validation of the Bangla Fear of COVID-19 Scale: Confirmatory Factor Analysis and Rasch Analysis. International journal of mental health and addiction. 2020; doi:10.1007/s11469-020-00289-x

5. Barrios I, Ríos-González C, O'Higgins M, González-Urbieta I, García O, Almirón-Santacruz J, et al. Psychometric properties of the Spanish version of the Fear of COVID-19 scale in Paraguayan population. Irish journal of psychological medicine. 2021; doi:10.1017/ipm.2021.5

6. Iversen MM, Norekvål TM, Oterhals K, Fadnes LT, Mæland S, Pakpour AH, et al. Psychometric Properties of the Norwegian Version of the Fear of COVID-19 Scale. International journal of mental health and addiction. 2021; doi:10.1007/s11469-020-00454-2

7. Masuyama A, Shinkawa H, Kubo T. Validation and Psychometric Properties of the Japanese Version of the Fear of COVID-19 Scale Among Adolescents. International journal of mental health and addiction. 2020; doi:10.1007/s11469-020-00368-z

8. Pretorius TB, Padmanabhanunni A, Stiegler N, Bouchard JP. Validation of the fear of COVID-19 scale in South Africa: Three complementary analyses. Annales medico-psychologiques. 2021; doi:10.1016/j.amp.2021.10.010

9. Al-Shannaq Y, Mohammad AA, Khader Y. Psychometric Properties of the Arabic Version of the Fear of COVID-19 Scale (FCV-19S) Among Jordanian Adults. International journal of mental health and addiction. 2021; doi:10.1007/s11469-021-00574-3

10. Soraci P, Ferrari A, Abbiati FA, Del Fante E, De Pace R, Urso A, et al. Validation and Psychometric Evaluation of the Italian Version of the Fear of COVID-19 Scale. International journal of mental health and addiction. 2020; doi:10.1007/s11469-020-00277-1

11. Alyami M, Henning M, Krägeloh CU, Alyami H. Psychometric Evaluation of the Arabic Version of the Fear of COVID-19 Scale. International journal of mental health and addiction. 2020; doi:10.1007/s11469-020-00316-x

12. Cavalheiro FRS, Sticca MG. Adaptation and Validation of the Brazilian Version of the Fear of COVID19 Scale. International journal of mental health and addiction. 2020; doi:10.1007/s11469-02000415-9

13. Mahmood QK, Jafree SR, Qureshi WA. The Psychometric Validation of FCV19S in Urdu and SocioDemographic Association with Fear in the People of the Khyber Pakhtunkhwa (KPK) Province in Pakistan. International journal of mental health and addiction. 2020; doi:10.1007/s11469-02000371-4

14. Mailliez M, Griffiths MD, Carre A. Validation of the French Version of the Fear of COVID-19 Scale and Its Associations with Depression, Anxiety, and Differential Emotions. International journal of mental health and addiction. 2021; doi:10.1007/s11469-021-00499-x

15. Winter T, Riordan BC, Pakpour AH, Griffiths MD, Mason A, Poulgrain JW, et al. Evaluation of the English Version of the Fear of COVID-19 Scale and Its Relationship with Behavior Change and Political Beliefs. International journal of mental health and addiction. 2020; doi:10.1007/s11469-02000342-9 
16. Wakashima K, Asai K, Kobayashi D, Koiwa K, Kamoshida S, Sakuraba M. The Japanese version of the Fear of COVID-19 scale: Reliability, validity, and relation to coping behavior. PloS one. 2020; doi:10.1371/journal.pone.0241958

17. Chang KC, Hou WL, Pakpour AH, Lin CY, Griffiths MD. Psychometric Testing of Three COVID-19Related Scales Among People with Mental IIIness. International journal of mental health and addiction. 2020; doi:10.1007/s11469-020-00361-6

18. Sakib N, Bhuiyan A, Hossain S, Al Mamun F, Hosen I, Abdullah AH, et al. Psychometric Validation of the Bangla Fear of COVID-19 Scale: Confirmatory Factor Analysis and Rasch Analysis. International journal of mental health and addiction. 2020; doi:10.1007/s11469-020-00289-x

19. Tzur Bitan D, Grossman-Giron A, Bloch Y, Mayer Y, Shiffman N, Mendlovic S. Fear of COVID-19 scale: Psychometric characteristics, reliability and validity in the Israeli population. Psychiatry research. 2020; doi:10.1016/j.psychres.2020.113100

20. Spitzer RL, Kroenke K, Williams JB, Löwe B. A brief measure for assessing generalized anxiety disorder: the GAD-7. Archives of internal medicine. 2006; doi:10.1001/archinte.166.10.1092

21. Kroenke K, Spitzer RL, Williams JB. The PHQ-9: validity of a brief depression severity measure. Journal of general internal medicine. 2001; doi:10.1046/j.1525-1497.2001.016009606.x

22. Schober P, Boer C, Schwarte LA. Correlation Coefficients: Appropriate Use and Interpretation. Anesthesia and analgesia. 2018; doi:10.1213/ane.0000000000002864

23. Irwing P, Booth T, Hughes J, editors. The Wiley handbook of psychometric testing: A multidisciplinary reference on survey, scale and test development. West Sussex: John Wiley \& Sons; 2018.

24. Goldberg LR, Velicer WF. Principles of exploratory factor analysis. Differentiating normal and abnormal personality. 2006;

25. Szüle B. Comparison of goodness measures for linear factor structures. Statisztikai Szemle. 2017;

26. Xia Y, Yang Y. RMSEA, CFI, and TLI in structural equation modeling with ordered categorical data: The story they tell depends on the estimation methods. Behavior Research Methods. 2019; doi:10.3758/s13428-018-1055-2

27. Kline RB. Principles and practice of structural equation modeling. London: Guilford Press; 2015.

28. Government H. Coronavirus information. 31.05.2021 ed. koronavirus.gov.hu2021.

29. Lin CY, Hou WL, Mamun MA, Aparecido da Silva J, Broche-Pérez Y, Ullah I, et al. Fear of COVID-19 Scale (FCV-19S) across countries: Measurement invariance issues. Nursing open. 2021; doi:10.1002/nop2.855

30. Chia T, Oyeniran OI, Iorfa SK. Validation of the fear of the COVID-19 scale in Nigeria: Implications for public health practice. Journal of Taibah University Medical Sciences. 2021; doi:10.1016/j.jtumed.2021.05.006

31. Reznik A, Gritsenko V, Konstantinov V, Khamenka N, Isralowitz R. COVID-19 Fear in Eastern Europe: Validation of the Fear of COVID-19 Scale. International journal of mental health and addiction. 2020; doi:10.1007/s11469-020-00283-3

Page 15/16 
32. Nazari N, Safitri S, Usak M, Arabmarkadeh A, Griffiths MD. Psychometric Validation of the Indonesian Version of the Fear of COVID-19 Scale: Personality Traits Predict the Fear of COVID-19. International journal of mental health and addiction. 2021; doi:10.1007/s11469-021-00593-0

33. Pilch I, Kurasz Z, Turska-Kawa A. Experiencing fear during the pandemic: validation of the fear of COVID-19 scale in Polish. PeerJ. 2021; doi:10.7717/peerj.11263

34. Stănculescu E. Fear of COVID-19 in Romania: Validation of the Romanian Version of the Fear of COVID-19 Scale Using Graded Response Model Analysis. International journal of mental health and addiction. 2021; doi:10.1007/s11469-020-00428-4

\section{Figures}

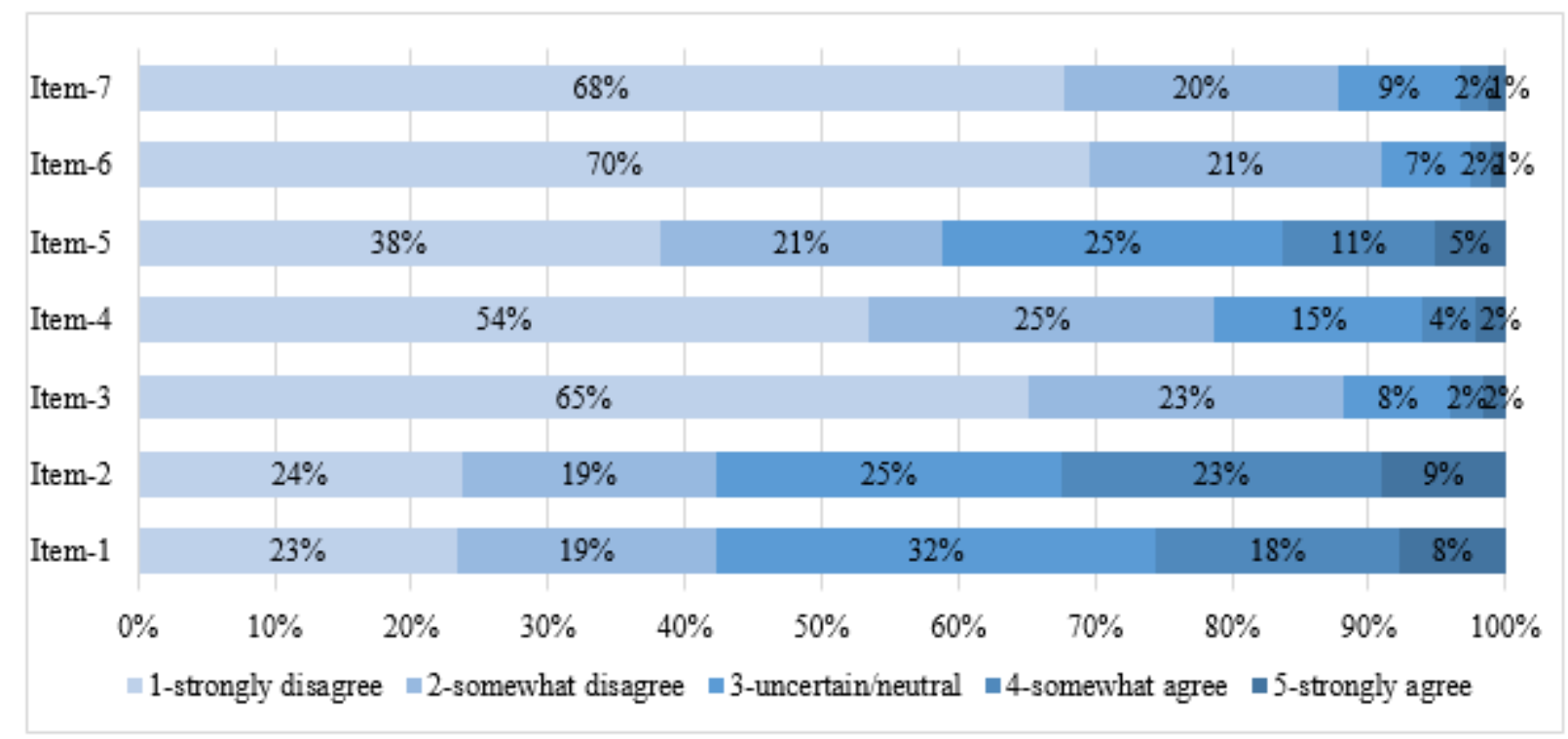

Figure 1

Distribution of responses among FCV-19 items

\section{Supplementary Files}

This is a list of supplementary files associated with this preprint. Click to download.

- additionalfile1FCV19covidCFA0224.docx 